\title{
HYDRATION STRUCTURE AND WATER EXCHANGE DYNAMICS OF Fe(II) ION IN AQUEOUS SOLUTION
}

\author{
Ahmed M. Mohammed ${ }^{*}$ \\ Department of Chemistry, Addis Ababa University, P.O. Box 1176, Addis Ababa, Ethiopia
}

(Received May 11, 2009; revised October 28, 2009)

\begin{abstract}
Computer simulation studies of the hydration structure and water exchange dynamics in the first hydration shell for $\mathrm{Fe}$ (II) in water are presented. The structure of the hydrated ion is discussed in terms of radial distribution functions, coordination numbers, and angular distributions. The average first-shell hydration structure is a 6-coordinate octahedron, in agreement with experimental results. The water exchange reaction around the $\mathrm{Fe}(\mathrm{II})$ ion in water was investigated using classical umbrella-sampling molecular dynamic simulations. The water exchange mechanism, estimates for reaction rate, as well as structural changes during the activation process are discussed. The water exchange mechanism proceeds via the $\mathrm{I}_{\mathrm{d}}$ mechanism. The water exchange rate constant at $298 \mathrm{~K}$ is estimated by the transition state theory to be $2.1 \times 10^{7} \mathrm{~s}^{-1}$, assuming a transmission coefficient of unity.
\end{abstract}

KEY WORDS: Hydration, Water exchange, Umbrella sampling, Rate constant, Iron(II) ion

\section{INTRODUCTION}

Understanding the phenomena of solvation of metal ions has been an important quest in many fields where this phenomenon has a relevant role [1-4]. Hence, investigations have been carried out to determine the structure and dynamics of metal ions in solution by a variety of spectroscopic techniques [5-7], scattering techniques [5, 8, 9], electrochemical techniques [10, 11] and by theoretical methods, mostly simulations of the Monte Carlo (MC), molecular dynamics (MD), and quantum mechanics/molecular mechanics (QM/MM) types [5, 12-23].

Computer simulation techniques, such as molecular dynamics (MD), have been used to study hydration structures of metal ions and their water exchange dynamics [12-23]. However, the type of metal under study and of ion-solvent interaction potentials have strong influence on their success. The most commonly used potentials are based on pairwise interaction energies derived by direct ab initio quantum chemical calculations which leads to an error of interaction energies in cation-water systems of at least $10 \%, 15 \%$ and $20 \%$ for mono-, di- and trivalent ions, respectively [24]. The failure of pairwise additivity for cation-water potentials, particularly for divalent and trivalent ions, has been handled in various ways [17-19, 22, 23]. However, the more exact approach is to supplement the pair potential energy function to be employed by many-body terms. In many cases, three-body potentials calculated by ab initio methods at least have reproduced properly the hydration structure [17-19].

The study of solvent exchange reactions is an important prerequisite in understanding the reactivity of metal ions in biological and chemical systems. The most fundamental and also most common reaction type is the water exchange in aqueous solutions. In such reactions a coordinating water molecule of the first hydration shell is replaced by a water molecule from the second shell. Langford and Gray [25] have devised a classification scheme to distinguish various types of the exchanges. The limiting reaction mechanisms associative (A) and dissociative (D) describe reactions in which an intermediate with increased or decreased hydration shell, respectively, is formed. The interchange (I) mechanism is divided into $\mathrm{I}_{\mathrm{a}}, \mathrm{I}$, and $I_{d}$ depending on whether bond breaking or bond foming is of more importance. Merbach et al. intensively used the activation volume $\Delta V^{\ddagger}$ to determine and classify the reaction mechanism by high-pressure nuclear magnetic resonance (NMR) experiments in accordance with the Langford-

*Corresponding author. E-mail: am_moha@chem.aau.edu.et 
Gray scheme [26]. Most water exchange rate constants of transition metal cations have been experimentally investigated by using NMR. However, several cations exchange first-shell water ligands very rapidly and therefore pose several problems for the successful application of the method. Furthermore, structural changes at the microscopic level are not directly accessible through NMR. There are some crude assumptions about the volume change in the theoretical basis of $\Delta V^{\ddagger}$, which leads to the structural transformations during the activation process [2-27]. Therefore, theoretical methods are necessary to supplement data that are obtained from experimental studies.

MD simulation techniques have also been important in providing insight into water exchange processes around hydrated metal ions [17, 28-33]. Water exchange processes of many metal ions often occur on timescales larger than the nanosecond range typical for standard MD simulations [26]. Therefore, observing the transition state (TS) is quite rare during a simulation leading to unreliable results. In order to increase the probability of finding high energy states and hence enhancing sampling efficiency in a specific region of phase space a biasing function driving particles along a chosen reaction coordinate may be applied. One powerful approach to adequately sample high energy, i.e. a transition state, is the umbrella-sampling technique [34, 35], which has been widely used to calculate reaction profiles for chemical processes in solution [31, 32, 36-39]. It has been successfully applied to study water exchange processes around other first row-transition metal ions in water [31-33]. In this technique, a suitable reaction coordinate is chosen and a series of independent simulations are performed by spanning the relevant phase space of the reaction coordinate. A biasing potential is imposed to restrain the system to the desired point on the reaction coordinate, and the potential parameters have to change for a series of simulations along an assumed reaction coordinate. To obtain the unbiased free energy profile, several methods are available; however, the most common and successful method is the weighted-histogram-analysis method (WHAM) [36, 40, 41] which is adopted in this study. By this method the potential of mean force (PMF) along the chosen reaction coordinate may be obtained, and structural and energetic properties like the transition state are determined.

In this study, 2-body (2BD) potential for $\mathrm{Fe}(\mathrm{II})-\mathrm{H}_{2} \mathrm{O}$ interaction and its 3-body (3BD) correction terms $\left(\mathrm{H}_{2} \mathrm{O}-\mathrm{Fe}(\mathrm{II})-\mathrm{H}_{2} \mathrm{O}\right)$ were evaluated by means of ab initio molecular orbital calculations and corresponding analytical functions were constructed. Standard MD simulation was carried out for $\mathrm{Fe}$ (II) in water using the 2-body potential and its 3-body correction function to study hydration structure of the Fe(II) ion. Furthermore, the present study investigates the water exchange processes around the Fe(II) ion in the aqueous solution. Emphasis is given on the illumination of the structural changes at the transition state during the replacement of a water molecule from the first shell by a water molecule from the second hydration shell (Figure 1). Free energy profile along the chosen reaction coordinate was determined and used to obtain the exchange mechanism and reaction rate of the water exchange process. In order to do sampling along a reaction coordinate umbrella-sampling technique was applied. The water exchange reaction is determined from the viewpoint of a dissociative unimolecular approach $\left(\mathrm{S}_{\mathrm{N}}{ }^{1}\right.$ in terms of standard organic chemistry nomenclature).

\section{COMPUTATIONAL DETAILS}

\section{Construction of ion-water pair potential}

Ab initio molecular orbital calculations were carried out at the unrestricted Hartree-Fock (UHF) level using the Gaussian 98 program [42]. The ECP basis set of Christiansen et al. [43] for Fe(II) and the DZP basis sets of Dunning [44] for water were employed. The experimental gas-phase 
geometry of $\mathrm{H}_{2} \mathrm{O}$ was used with the $\mathrm{O}-\mathrm{H}$ distance of $0.9601 \AA$ and the $\mathrm{H}-\mathrm{O}-\mathrm{H}$ angle of $104.47^{\circ}$ [45].

To calculate the 2-body interaction energies between $\mathrm{Fe}\left(\right.$ III) and $\mathrm{H}_{2} \mathrm{O}$, the position of the $\mathrm{Fe}$ (II) ion was varied around the $\mathrm{H}_{2} \mathrm{O}$ molecule by fixing the $\mathrm{O}$ atom at the origin, two $\mathrm{H}$ atoms on the $x z$ plane, and the $C_{2 v}$ axis of $\mathrm{H}_{2} \mathrm{O}$ on the $z$ axis of the Cartesian coordinate system. The values of the $\mathrm{Fe}(\mathrm{II})-\mathrm{O}$ distance $\left(r_{\mathrm{FeO}}\right)$, the angle between the $\mathrm{O}-\mathrm{Fe}$ vector and the $z$ axis $(\theta)$, and the angle between the $x$ axis and the projection of the O-Fe vector onto the $x y$ plane $(\phi)$ were varied over the ranges $1.5 \AA \leq r_{\mathrm{FeO}} \leq 15.0 \AA, 0^{\circ} \leq \theta \leq 180^{\circ}$, and $0^{\circ} \leq \phi \leq 90^{\circ}$. The 2-body interaction energies $\left(E_{2 \mathrm{bd}}\right)$ were calculated by subtracting the SCF energies $\left(E_{\mathrm{Fe}}\right.$ and $\left.E_{\mathrm{W}}\right)$ of isolated $\mathrm{Fe}(\mathrm{II})$ and $\mathrm{H}_{2} \mathrm{O}$ from that $\left(E_{\mathrm{FeW}}\right)$ of $\left[\mathrm{Fe}\left(\mathrm{H}_{2} \mathrm{O}\right)\right]^{2+}$, as expressed by Eq. 1 .

$$
E_{2 \mathrm{bd}}=E_{\mathrm{FeW}}-\left(E_{\mathrm{Fe}}+E_{\mathrm{W}}\right)
$$

To represent the $E_{2 \text { bd }}$ values by an analytical function, various functions were tested to fit to the $E_{2 \mathrm{bd}}$ values by a least-squares optimization using the Levenberg-Marquardt algorithm. The best reproducibility was obtained using a function composed of four $r^{-m}$ terms for the nonCoulombic interaction in addition to the Coulombic interaction, as expressed by Eq. 2,

$$
\begin{aligned}
E_{2 \mathrm{bd}}= & \frac{Q_{\mathrm{Fe}} Q_{\mathrm{O}}}{r_{\mathrm{FeO}}}+A_{\mathrm{O}} r_{\mathrm{FeO}}{ }^{-5}+B_{\mathrm{O}} r_{\mathrm{FeO}}{ }^{-7}+C_{\mathrm{O}} r_{\mathrm{FeO}}{ }^{-9}+D_{\mathrm{O}} r_{\mathrm{FeO}}{ }^{-12}+ \\
& \sum_{i=1}^{2}\left(\frac{Q_{\mathrm{Fe}} Q_{\mathrm{H}_{\mathrm{i}}}}{r_{\mathrm{FeH}_{\mathrm{i}}}}+A_{\mathrm{H}}{r_{\mathrm{FeH}}}^{-5}+B_{\mathrm{H}} r_{\mathrm{Fe} \mathrm{H}_{i}}{ }^{-7}+C_{\mathrm{H}}{r_{\mathrm{FeH}}}^{-9}+D_{\mathrm{H}_{\mathrm{FeH}_{i}}}{ }^{-12}\right)
\end{aligned}
$$

where $Q$ is the atomic net charge, $r_{\mathrm{FeH}}$ is the distance between $\mathrm{Fe}$ and $\mathrm{H}$, and $A, B, C$, and $D$ are optimization parameters. The values of -0.6596 and 0.3298 were adopted for $Q_{\mathrm{O}}$ and $Q_{\mathrm{H}}$, respectively, from the central-force $(\mathrm{CF})$ model for $\mathrm{H}_{2} \mathrm{O}$ [46]. The value of $Q_{\mathrm{Fe}}$ was assumed to be 2 . $E_{2 \mathrm{bd}}$ values near the global energy minimum were emphasized during the least-squares procedure by assigning an appropriate weighting factor. $E_{2 \mathrm{bd}}$ values above $30 \mathrm{kcal} \mathrm{mol}{ }^{-1}$ were excluded in the optimization of the function. The optimized potential parameters are given in Table 1 . The average absolute residual of the fit was $1.4 \mathrm{kcal} \mathrm{mol}^{-1}$. The global energy minimum of the fitted function was found to be $-81.6 \mathrm{kcal} \mathrm{mol}^{-1}$ at $r_{\mathrm{FeO}}=1.97 \AA$ and $\theta=\phi=0^{\circ}$.

Construction of 3-body correction term

The 3-body correction energy ( $\left.E_{3 \mathrm{bd}}\right)$ was calculated according to Eq. 3,

$$
E_{3 \mathrm{bd}}=E_{\mathrm{FeW}_{\mathrm{i}} \mathrm{W}_{\mathrm{j}}}-\left(E_{\mathrm{Fe}}+2 E_{\mathrm{W}}\right)-\left(E_{\mathrm{FeW}_{\mathrm{i}}}+E_{\mathrm{FeW}_{\mathrm{j}}}\right)-E_{\mathrm{W}_{\mathrm{i}} \mathrm{W}_{\mathrm{j}}}
$$

where $E_{\mathrm{FeW}_{\mathrm{i}} \mathrm{W}_{\mathrm{j}}}$ is the SCF energy for $\left[\mathrm{Fe}\left(\mathrm{H}_{2} \mathrm{O}\right)_{2}\right]^{2+}, E_{\mathrm{FeW}_{\mathrm{i}}}$ and $E_{\mathrm{FeW}_{\mathrm{j}}}$ are the 2-body interaction energies, calculated using the previously developed analytical function (Eq. 2), and $E_{\mathrm{W}_{\mathrm{i}} \mathrm{w}_{\mathrm{j}}}$ is the intermolecular potential between $\mathrm{H}_{2} \mathrm{O}$ molecules computed using the $\mathrm{CF} 2$ model [47]. The SCFenergy calculations were performed by varying independently both $\mathrm{Fe}-\mathrm{O}$ distance $\left(2.0 \leq r_{\mathrm{FeO}} \leq\right.$ $6.0 \AA$ ) and the $\mathrm{O}-\mathrm{Fe}-\mathrm{O}$ angle $\left(60^{\circ} \leq \psi \leq 180^{\circ}\right)$. The dipole moments of both $\mathrm{H}_{2} \mathrm{O}$ molecules were fixed to point toward the $\mathrm{Fe}$ (II) ion for all configurations. Almost all of the $E_{3 \mathrm{bd}}$ values were found to be positive for the geometries employed in this study. The $E_{3 \mathrm{bd}}$ value decreases with increasing $r_{\mathrm{FeO}}$ and becomes almost $0 \mathrm{kcal} \mathrm{mol}^{-1}$ when either $r_{\mathrm{FeO}}$ approaches to $6.0 \AA$. Furthermore, given a set of two $r_{\mathrm{FeO}}$ distances, the $E_{3 \mathrm{bd}}$ value fell off with increasing distance between the two $\mathrm{H}_{2} \mathrm{O}$ molecules. The $E_{3 \text { bd }}$ function can be expressed by Eq. 4 , 
$E_{3 \mathrm{bd}}=\left\{\begin{array}{l}F \exp -G\left(r_{\mathrm{FeO}_{\mathrm{i}}}+r_{\mathrm{FeO}_{\mathrm{j}}}\right) \times \exp \left(-\mathrm{Hr} r_{\mathrm{ij}}\right)\left[\left(R_{\mathrm{CL}}-r_{\mathrm{FeO}_{\mathrm{i}}}\right)^{2}\left(R_{\mathrm{CL}}-r_{\mathrm{FeO}_{\mathrm{j}}}\right)^{2}\right] ; R_{\mathrm{FeO}}<R_{\mathrm{CL}} \& R_{\mathrm{FeO}}<R_{\mathrm{CL}}, \\ 0 ; R_{\mathrm{FeO}}>R_{\mathrm{CL}} \text { or } R_{\mathrm{FeO}}>R_{\mathrm{CL}}\end{array}\right.$

where $F, G$, and $H$ are fitting parameters, $r_{i j}$ is the distance between two oxygen atoms of $\mathrm{H}_{2} \mathrm{O}$ molecules, and $R_{\mathrm{CL}}$ is the cutoff limit of $6.0 \AA$ for the 3-body correction function. The final term in Eq. 4 guarantees that $E_{3 \mathrm{dd}}$ vanishes if $r_{\mathrm{FeO}_{\mathrm{i}}}$ or $r_{\mathrm{FeO}_{\mathrm{j}}}$ become larger than $R_{\mathrm{CL}}$. The analytical function of Eq. 4 was fitted to the $E_{3 \mathrm{bd}}$ values by a least-squares optimization, and the final parameters are given in Table 1 . The average absolute residual of the fit was $0.9 \mathrm{kcal} \mathrm{mol}^{-1}$.

Table 1. Parameters for two-body potential and three-body correction function of Fe(II)-water interactions.

\begin{tabular}{|c|c|c|c|c|c|c|c|c|}
\hline \multicolumn{9}{|c|}{ 2-body } \\
\hline & Atom & \multicolumn{2}{|c|}{$\mathrm{A}(\mathrm{kcal} / \mathrm{mol})^{-\mathrm{A}}$} & \multicolumn{2}{|c|}{$\mathrm{B}(\mathrm{kcal} / \mathrm{mol})^{-\mathrm{B}}$} & \multicolumn{2}{|c|}{$\mathrm{C}(\mathrm{kcal} / \mathrm{mol})^{-\mathrm{C}}$} & $\mathrm{D}(\mathrm{kcal} / \mathrm{mol})^{-\mathrm{D}}$ \\
\hline \multirow[t]{2}{*}{$\mathrm{Fe}$} & $\mathrm{O}$ & \multicolumn{2}{|c|}{-6245.86} & \multicolumn{2}{|c|}{31739.50} & \multicolumn{2}{|c|}{-42921.66} & 21788.60 \\
\hline & $\mathrm{H}$ & \multicolumn{2}{|c|}{-19.45} & \multicolumn{2}{|c|}{1668.81} & \multicolumn{2}{|c|}{-3686.05} & 3076.45 \\
\hline \multicolumn{9}{|c|}{ 3-body } \\
\hline \multirow{2}{*}{\multicolumn{3}{|c|}{$\mathrm{H}_{2} \mathrm{O}-\mathrm{Fe}(\mathrm{II})-\mathrm{H}_{2} \mathrm{O}$}} & \multicolumn{2}{|c|}{$F\left(\mathrm{kcal} / \mathrm{mol}^{-4}\right)$} & \multicolumn{2}{|c|}{$G\left(\AA^{-1}\right)$} & \multicolumn{2}{|c|}{$H\left(\AA^{-1}\right)$} \\
\hline & & & \multicolumn{2}{|c|}{0.2574718} & \multicolumn{2}{|c|}{0.2199461} & \multicolumn{2}{|c|}{0.3407707} \\
\hline
\end{tabular}

\section{Standard MD simulation}

The standard MD simulation method applied in this study was described in detail in previous paper [22] and will only be briefly reviewed here.

The simulation system consisting of one Fe(II) ion and 499 water molecules in a cubic simulation box of $15065.6 \AA^{3}$ subjected to periodic boundary conditions. The simulations were performed in the $N V T$ ensemble with a time step of $0.2 \mathrm{fs}$. The density of the simulation box was set to the experimental value of pure water at $298.16 \mathrm{~K}\left(0.997 \mathrm{~g} \mathrm{~cm}^{-3}\right)$. Long range interactions were treated by the reaction field method [25]. The CF2 model was used for the intermolecular potential between $\mathrm{H}_{2} \mathrm{O}$ molecules, and the intramolecular potential of $\mathrm{H}_{2} \mathrm{O}$ developed by Bopp et al. was employed to reproduce correctly liquid-phase vibrational frequencies [48]. In order to construct the initial configuration, the $\mathrm{O}$ atoms of $\mathrm{H}_{2} \mathrm{O}$ were placed in the simulation box according to the face-centered cubic lattice. The $\mathrm{H}$ atoms were arranged with random configuration of $\mathrm{H}_{2} \mathrm{O}$ molecules. A total of 400,000 steps ( $80 \mathrm{ps}$ ) were first processed using only the 2-body potential, and the system was confirmed to be energetically equilibrated. A further 400,000 steps ( $80 \mathrm{ps}$ ) were sampled to evaluate structural properties. The simulation was continued for further 400,000 steps ( $80 \mathrm{ps}$ ) of equilibrium after the inclusion of the 3-body correction. All energies were confirmed to become stable within 5 ps of equilibrium. A further 1,000,000 steps ( $0.2 \mathrm{~ns})$ simulation was carried out for the statistical sampling.

\section{Umbrella-sampling MD simulations}

A randomly chosen water molecule from the first hydration shell was moved to the second hydration under the influence of the umbrella potential $V_{\text {umb }}$ (Figure 1):

$$
V_{\mathrm{umb}}\left(r_{o}\right)=\frac{k}{2}\left(r_{o b}-r_{o}\right)^{2}
$$


where $r_{o}$ is the instantaneous $\mathrm{Fe}-\mathrm{O}$ distance between $\mathrm{Fe}(\mathrm{II})$ and a dissociating water molecule. The parameter $k$ denotes the force constant and $r_{o b}$ is the restrained $\mathrm{Fe}-\mathrm{O}$ distance. The distance $r_{o}$ was varied between $2.0 \AA$ and $4.5 \AA$ to cover the full range between first and second hydration shells. The force constant $k$ was adjusted according to $r_{o}$, i.e. $k$ was set to high values close to the transition state and to small values at minima in the PMF. The unbiased probability distribution $\left\langle\rho\left(r_{o}\right)>\right.$ was obtained by the WHAM [35, 41, 42] method to calculate the PMF according to Eq. 6

$$
W\left(r_{o}\right)=-k_{\mathrm{B}} T \ln \left\langle\rho\left(r_{o}\right)\right\rangle+C
$$

where $k_{\mathrm{B}}$ is the Boltzmann constant, $T$ the absolute temperature, and $C$ an arbitrary constant. An estimate for the reaction rate constant $k_{\mathrm{ex}}$ may then be determined from the free energy difference $\Delta G^{\dot{t}}$ between the ground and transition state via the classical Eyring equation (Eq. 7)

$$
k_{\mathrm{ex}}=\kappa \frac{k_{B} T}{h} \exp \left(-\frac{\Delta^{\ddagger} G}{\mathrm{RT}}\right)
$$

where $\kappa$ is the transmission coefficient, $k_{\mathrm{B}}$ is the Boltzmann constant, $h$ is the Planck constant, $\mathrm{R}$ is the gas constant, and $T$ is the absolute temperature.

The simulation protocol was the same as in the standard MD simulation. The starting configuration of the system was taken from the last configuration of the standard simulation obtained using the corrected 2-body potential. In total, 15 independent MD simulations were carried out with 200 ps each reserved for data collection after the system was allowed to reach the equilibrium within 2 ps. Several test simulations have been performed to ensure the independence of the chosen parameters.

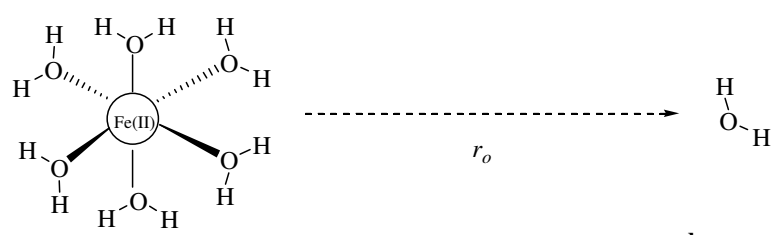

$1^{\text {st }}$ hydration shell

$2^{\text {nd }}$ hydration shell

Figure 1. Removal of a water molecule from the first hydration shell.

\section{RESULTS AND DISCUSSION}

\section{Structural properties}

The $\mathrm{Fe}$ (II)-O and $\mathrm{Fe}(\mathrm{II})-\mathrm{H}$ radial distribution functions (RDFs), and their running integration numbers obtained from the standard MD simulation are displayed in Figure 2. The main structural parameters are listed and compared with experimental and other simulation investigations in Table 2. The first Fe(II)-O RDF peak which is related to the first hydration shell reaches its maximum at $2.21 \AA$ and the second peak related to the second hydration shell reaches its maximum at $4.64 \AA$, clearly separated from the first hydration sphere. Between the first and second shells, it becomes zero for more than $1 \AA$, corresponding to slow intershell water exchange processes. But the fact that the $\mathrm{Fe}(\mathrm{II})-\mathrm{O}$ RDF does not go down to zero once the 
second hydration shell is formed, suggests that this shell must easily interchange water molecules with outer hydration spheres or the bulk.

Table 2. Hydration structure parameters of the Fe(II) ion in water determined by standard molecular simulation and experimental methods.

\begin{tabular}{|c|c|c|c|}
\hline Characteristic & Method & Values & Ref. \\
\hline \multirow[t]{9}{*}{$\mathrm{R}_{1(\mathrm{Fe}-\mathrm{O})} \max (\AA)^{\mathrm{a}}$} & QM/MM-MD & 2.10 & [49] \\
\hline & $\mathrm{MD}(3 \mathrm{BD})^{\mathrm{b}}$ & 2.15 & [50] \\
\hline & $\mathrm{MD}(3 \mathrm{BD})$ & 2.21 & This work \\
\hline & $\mathrm{MD}(\mathrm{EP})$ & $2.11-2.27$ & [51] \\
\hline & $\mathrm{MD}(\mathrm{PCM})$ & 2.15 & [52] \\
\hline & $\mathrm{MC}(\mathrm{PCM})$ & 2.10 & [53] \\
\hline & $\mathrm{MD}(2 \mathrm{BD})$ & 2.13 & This work \\
\hline & ND & 2.12 & [54] \\
\hline & $\mathrm{XD}, \mathrm{ND}, \mathrm{EX}$ & $2.10-2.28$ & [5] \\
\hline \multirow[t]{4}{*}{$\mathrm{R}_{2(\mathrm{Fe}-\mathrm{O})} \max (\AA)$} & QM/MM-MD & 4.50 & [49] \\
\hline & $\mathrm{MD}(3 \mathrm{BD})$ & 4.60 & [50] \\
\hline & $\mathrm{MD}(3 \mathrm{BD})$ & 4.61 & This work \\
\hline & $\mathrm{MD}(2 \mathrm{BD})$ & 4.35 & This work \\
\hline \multirow[t]{2}{*}{$\mathrm{R}_{1(\mathrm{Fe}-\mathrm{H})} \max (\AA)$} & $\mathrm{MD}(3 \mathrm{BD})$ & 2.95 & This work \\
\hline & $\mathrm{MD}(2 \mathrm{BD})$ & 2.86 & This work \\
\hline \multirow[t]{2}{*}{$\mathrm{R}_{2(\mathrm{Fe}-\mathrm{H})} \max (\AA)$} & $\mathrm{MD}(3 \mathrm{BD})$ & 5.20 & This work \\
\hline & $\mathrm{MD}(2 \mathrm{BD})$ & 4.95 & This work \\
\hline \multirow[t]{6}{*}{$\mathrm{N}_{1} / \mathrm{N}_{2}{ }^{\mathrm{b}}$} & $\mathrm{MD}(\mathrm{QM} / \mathrm{MM})$ & $6.0 / 12.4$ & [49] \\
\hline & $\mathrm{MD}(3 \mathrm{BD})$ & $6.0 / 12.9$ & [50] \\
\hline & $\mathrm{MC}(\mathrm{PCM})$ & $6.0 / 13.0$ & [53] \\
\hline & $\mathrm{MD}(3 \mathrm{BD})$ & $6.0 / 14.5$ & This work \\
\hline & $\mathrm{MD}(2 \mathrm{BD})$ & $8.0 / 19.0$ & This work \\
\hline & $\mathrm{XD}, \mathrm{ND}, \mathrm{EX}$ & $6.0 / 12.0$ & [5] \\
\hline
\end{tabular}

${ }^{\mathrm{a}} \mathrm{R}_{1}$ max \& $\mathrm{R}_{2}$ max denote the distances of the first and second RDF maxima; respectively. ${ }^{\mathrm{b}} \mathrm{N}_{1}$ and $\mathrm{N}_{2}$ denote the first and second shell coordination numbers. The methods are abbreviated as follows: ND; neutron diffraction; XD; X-ray diffraction; EX; EXAFS; QM/MM; quantum mechanical/molecular mechanical; MD; molecular dynamics; MC; Monte Carlo. Potential models adopted; are referred: 2BD; classical pair potential; 3BD classical pair potential plus three-body correction function; EP; empirical potential; PCM; polarizable continuum model.

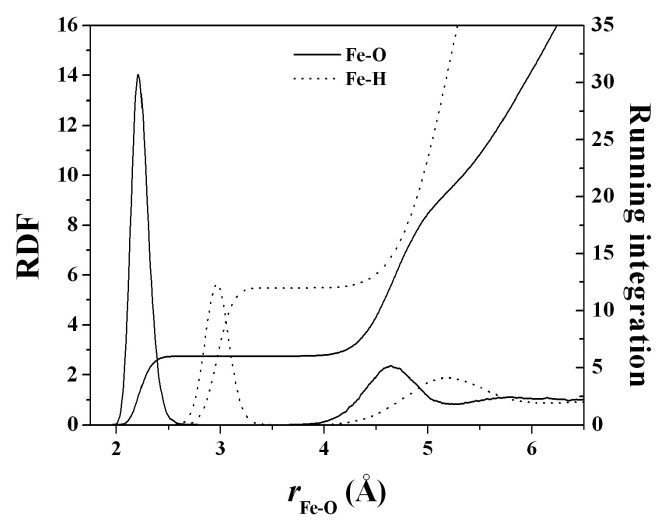

Figure 2. $\mathrm{Fe}(\mathrm{II})-\mathrm{O}$ and $\mathrm{Fe}(\mathrm{II})-\mathrm{H}$ radial distribution functions and their running integration numbers obtained by the standard MD simulation.

Bull. Chem. Soc. Ethiop. 2010, 24(2) 
The presence of two hydration shells is also clearly shown in the Fe(II)-H RDF (Figure 2). The first peak is centered at $2.96 \AA$ and the second at $5.18 \AA$. The shift of the peaks in Fe(II)-H $\mathrm{RDF}$ to larger distances with respect to the corresponding oxygen peaks indicates that especially in the first shell, the water molecules are well oriented to obey the dominant ion-water interactions with their oxygen atoms pointing to the ion.

The coordination number distribution (CND) probability obtained by the standard MD simulation is shown in Figure 3. In the first coordination sphere, only the coordination number 6 is observed. The second coordination sphere hydration shell contains on average 14.5 water molecules, implying that every first shell water molecule interacts with about 2.4 water molecules. This reveals that orientation and binding energy of these water molecules are mainly determined by hydrogen bonding.

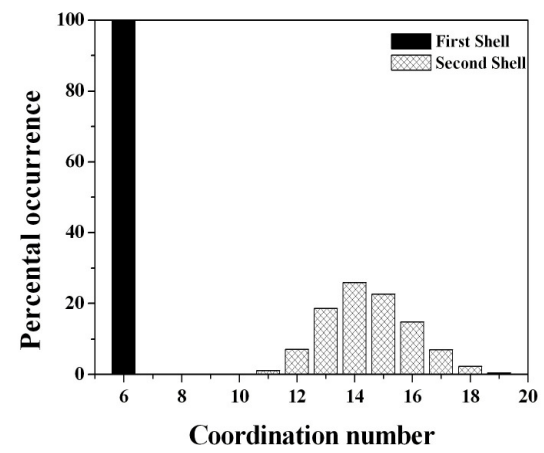

Figure 3. First and second shell coordination number distribution of hydrated Fe(II) obtained by the standard MD simulation.

The probability of finding $\mathrm{O}-\mathrm{Fe}-\mathrm{O}$ angle $(\theta)$ in the first hydration shell, the first-shell angular distribution function (ADF), obtained from the standard simulation is shown in Figure 4 as a function of $1-\cos \theta$. Two well-defined peaks can be observed at the peak maxima of $90^{\circ}$ and $180^{\circ}$. The running integration numbers show that the area ratio of the two peaks is $4: 1$. These results indicate that the hydration geometry around the $\mathrm{Fe}(\mathrm{II})$ ion is on average a 6-coordinate octahedral, supporting the above observation and in agreement with many experimental results Table 2.

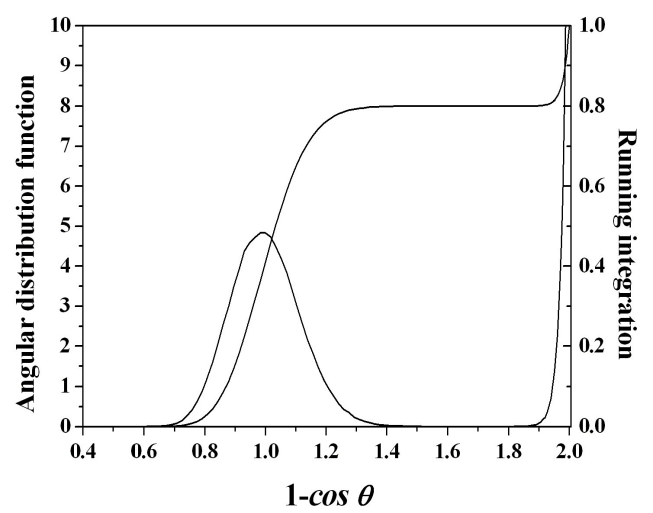

Figure 4. First-shell angular distribution functions for $\mathrm{O}-\mathrm{Fe}-\mathrm{O}(\theta)$ in the first hydration shell of the $\mathrm{Fe}(\mathrm{II})$ ion as a function of $1-\cos \theta$ obtained by the standard MD simulation.

Bull. Chem. Soc. Ethiop. 2010, 24(2) 
Potential of mean force $(P M F)$ and rate constant

In Table 3, the free energy profile (PMF) along the chosen $\mathrm{M}-\mathrm{O}$ (distance of a dissociating water molecule) coordinate for the $\mathrm{Fe}^{2+}$ ion in comparison with $\mathrm{Mn}^{2+}, \mathrm{Co}^{2+}$ and $\mathrm{Ni}^{2+}$ is depicted. The PMF has characteristic shape with a first minimum at $2.21 \AA$ that corresponds to the average $\mathrm{Fe}(\mathrm{II})-\mathrm{O}$ distance for the first hydration shell (Figure 5), in agreement with the value obtained by the standard MD simulation in Table 2 . The second minimum describes a recovered 6-coordinate octahedral hydration in the first shell; however, at this point the dissociating water molecule has left the first shell and replaced by a water molecule from the second shell.

Table 3. Exchange rate and structural parameters for $\mathrm{Mn}^{2+}, \mathrm{Co}^{2+}, \mathrm{Fe}^{2+}, \mathrm{Ni}^{2+}$ and $\mathrm{Zn}^{2+}$ during the activation process at $298.16 \mathrm{~K}$.

\begin{tabular}{|c|c|c|c|c|c|}
\hline Parameter/Unit & $\mathrm{Mn}^{2+\mathrm{a}}$ & $\mathrm{Co}^{2+\mathrm{a}}$ & $\mathrm{Fe}^{2+}$ & $\mathrm{Ni}^{2+\mathrm{a}}$ & $\mathrm{Zn}^{2+\mathrm{b}}$ \\
\hline $\mathrm{k}_{\mathrm{ex}} / \mathrm{s}^{-1}$ & $4.6 \times 10^{9}$ & $1.4 \times 10^{8}$ & $2.1 \times 10^{7 \mathrm{c}}$ & $1.4 \times 10^{7}$ & $4.1 \times 10^{8}$ \\
\hline$\Delta G^{\ddagger} / \mathrm{kJ} \mathrm{mol}^{-1}$ & 17.9 & 26.6 & 31.3 & 32.4 & 23.6 \\
\hline$r_{\mathrm{O}} / \AA \AA A, \mathrm{GS}$ & 2.33 & 2.26 & 2.21 & 2.24 & 2.23 \\
\hline$r_{\mathrm{O}} / \AA \AA A, \mathrm{TS}$ & 3.1 & 3.1 & 3.24 & 3.25 & 3.34 \\
\hline$\Delta r_{\mathrm{O}} / \AA$ & +0.77 & +0.84 & +1.03 & +1.01 & +1.11 \\
\hline$N_{S}{ }^{\mathrm{d}}, \mathrm{TS}$ & 5.98 & 5.6 & 5.40 & 5.35 & 5.05 \\
\hline$r_{S}^{\mathrm{e}} / \AA \AA \AA, T S$ & 2.36 & 2.25 & 2.17 & 2.20 & 2.17 \\
\hline$r_{S}-r_{O}(G S) / \AA$ & +0.03 & -0.01 & -0.04 & -0.04 & -0.06 \\
\hline
\end{tabular}

${ }^{\mathrm{a}}$ Ref. 31. ${ }^{\mathrm{b}}$ Ref. $32 .{ }^{\mathrm{c}}$ The experimental values is $4.4 \times 10^{6} \mathrm{~s}^{-1}$, ref. $26 .{ }^{\mathrm{d}}$ number of spectator molecules. ${ }^{\mathrm{e}}$ average distance of the spectator molecules in the first shell.

The PMF maxima corresponding to the transition state of the water-exchange process is located at $3.24 \AA$. The free energy of activation $\left(\Delta G^{\ddagger}\right)$, the energy difference between the ground state (first PMF minimum) and the transition state (first PMF maximum), is $31.25 \mathrm{~kJ} / \mathrm{mol}$ (7.47 $\mathrm{kcal} / \mathrm{mol}$ ). According to the transition-state theory (Eq. 7), the water exchange rate constant $k_{e x}$ for $\mathrm{Fe}$ (II) ion at $298.16 \mathrm{~K}$ is $2.1 \times 10^{7} \mathrm{~s}^{-1}$, assuming a transmission coefficient, $\kappa$, to be unity. This value, considering the uncertainty of $k$ and the simplicity of the potential functions used in this study, is quite reasonable.

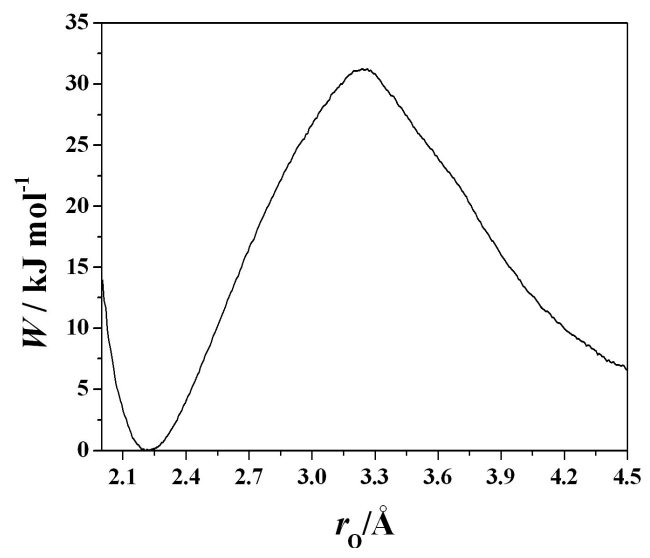

Figure 5. Potential of mean force (PMF) for water exchange process of around Fe(II) ion.

Bull. Chem. Soc. Ethiop. 2010, 24(2) 
Furthermore, the absence of an intermediate in the PMF (Figure 5) suggests that the water exchange process is taking place via the interchange (I) mode of the mechanism.

\section{Structural properties of the transition state}

In Figure 6 the $\mathrm{Fe}(\mathrm{II})-\mathrm{O}$ RDF and its running integration number close to the transition state is shown. The sharp peak at $3.24 \AA$ represents the dissociating water molecule. According to the running integration number, $\mathrm{Fe}$ (II) has a hydration number of 5.4 (excluding the dissociating water molecule) at the distance of the transition state of $3.24 \AA$ with the average distance of the spectator ligands $\left(r_{s}\right)$ of $2.17 \AA$, i.e. smaller than the ground state (GS) by $0.04 \AA$ (Table 3 ). This indicates that the number of water molecules in the first hydration shell at the transition state is less than in the ground state, suggesting the dissociative mode of the activation.

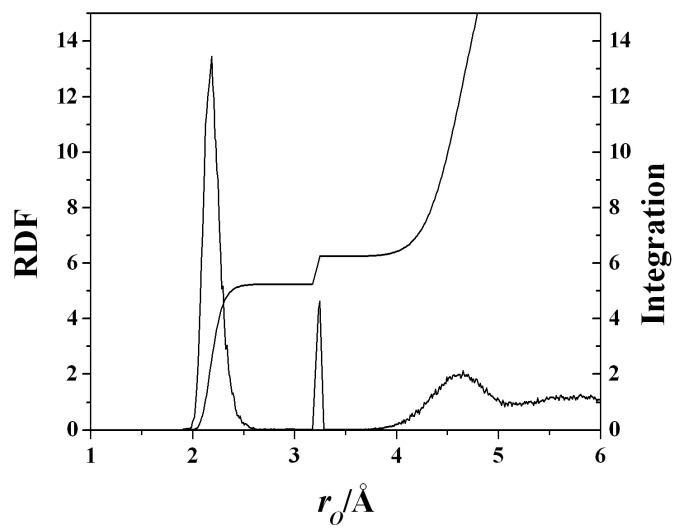

Figure 6. Radial distribution function with running integration of the $\mathrm{Fe}(\mathrm{II})-\mathrm{O}$ pair for the configuration with the $r_{o}$ value of $3.24 \pm 0.02 \AA$.

The average number of spectator molecules $\left(N_{s}\right)$ in the first hydration shell as a function of $r_{o}$ is shown in Figure 7. This numbers are obtained from the first-shell plateau of the running integration of RDFs, by excluding the dissociating water molecule. For $r_{o}$ less than $3.24 \AA$ (the $\mathrm{Fe}(\mathrm{II})-\mathrm{O}$ distance at the transition state), $N_{s}$ remains 5 , and for $r_{o}>3.24 \AA$ it increases to 6 , indicating the entrance of a water molecule from the second to the first hydration shell. This further demonstrates that the water exchange process for $\mathrm{Fe}(\mathrm{II})$ proceeds via the dissociative mode of the activation. The water exchange reaction around $\mathrm{Fe}(\mathrm{II})$ ion, therefore, proceeds via an $I_{d}$ mechanism in agreement with the experimental observation [26]. 

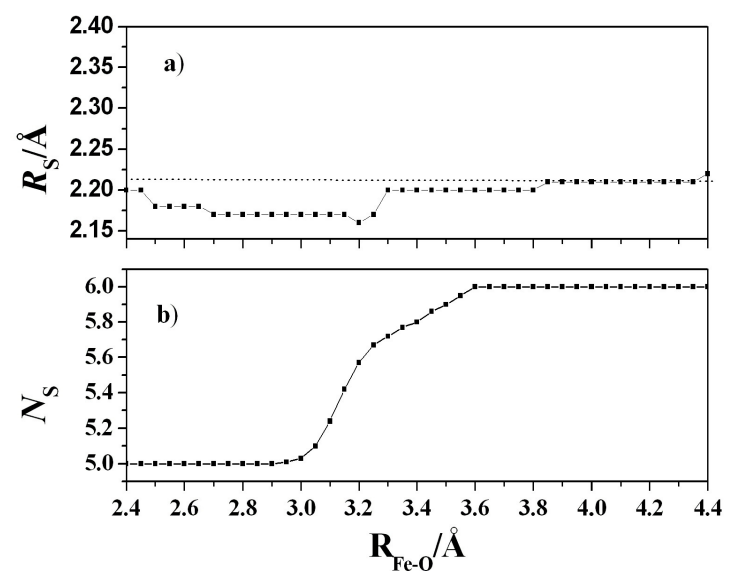

Figure 7. The (a) average $\mathrm{Fe}-\mathrm{O}$ peak maximum $\left(R_{\mathrm{s}}\right)$ and (b) number of spectator ions $\left(N_{\mathrm{s}}\right)$ as a function of $R_{o}$ for $\mathrm{Fe}$ (II)-water. The dotted horizontal line denotes in (a) represent the average $\mathrm{Fe}-\mathrm{O}$ distance of the first hydration shell in the ground state.

\section{CONCLUSIONS}

The first shell coordination numbers and ion-ligand distances obtained with the standard MD simulation including 3-body effects are in good agreement with the experimental data.

Based on the structural analysis of the first shell and number of spectator water molecules at the transition state, water exchange reaction around $\mathrm{Fe}(\mathrm{II})$ ion proceeds via $\mathrm{I}_{\mathrm{d}}$ mechanism in agreement with experimental observations. The water exchange rate constant is relatively high $\left(2.1 \times 10^{7} \mathrm{~s}^{-1}\right)$ but it is reasonable given the unknown transmission coefficient and the assumptions made in constructing the Fe(II)-water potential functions. In general, these results demonstrate that the umbrella-sampling MD simulation is a reliable tool to study ligandexchange processes around metal ions, not only where experimental investigation is impossible or difficult, but also processes which cannot be studied by standard MD simulations.

\section{AKNOWLEDGEMENTS}

The author is grateful to the Department of Chemistry, Addis Ababa University for the computational facilities.

\section{REFERENCES}

1. Marcus, Y. Ion Solvation, Wiley: Chichester; 1986; chapters 4 and 6.

2. Burgess, J. Metal Ions in Solution, Wiley: Chichester; 1987.

3. Creighton, T.E. Proteins: Structure and Molecular Properties, 2nd ed., Freeman: New York; 1983.

4. Babu, Y.S.; Sack, J.S.; Greenough, T.J.; Bugg, C.E.; Means, A.R.; Cook, W.J. Nature 1985, $315,37$.

5. Ohtaki, H.; Radnai, T. Chem. Rev. 1993, 93, 1157. 
6. Enderby, J.E.; Neilson, G.W. Rep. Prog. Phys. 1981, 44, 593.

7. Aizawa, S.; Matsuda, K.; Tajima, T.; Maeda, M.; Sugata, T.; Funahashi, S. Inorg. Chem. 1995, 34, 2042.

8. Ozutsumi, K.; Koide, M.; Suzuki, H.; Ishiguro, S. J. Phys. Chem. 1993, 97, 500.

9. Cotton, F.A.; Daniels, L.M.; Murillo, C.A.; Quesada, J.F. Inorg. Chem. 1993, 32, 4861.

10. Conway, B.E. Ionic Hydration in Chemistry and Biophysics, Elsevier: Amsterdam; 1981.

11. Amis, E.S.; Hinton, J.F. Solvent Effects on Chemical Phenomena, Academic: New York; 1973.

12. Marini, G.W.; Liedl, K.R.; Rode, B.M. J. Phys. Chem. A 1999, 103, 11387.

13. Kowall, T.; Foglia, F.; Helm, L.; Merbach, A.E. J. Am. Chem. Soc. 1995, 117, 3790.

14. Marx, D.; Sprik, M.; Parrinello, M. Chem. Phys. Lett. 1997, 273, 360.

15. Kerdcharoen, T.; Liedl, K.R.; Rode, B.M. Chem. Phys. 1996, 211, 313.

16. Martínez, J.M.; Cobos, J.H.; Martin, H.S.; Pappalardo, R.R.; Blake, I.O. Sánchez Marcos, E. J. Chem. Phys. 2000, 112, 2339.

17. Inada, Y.; Mohammed, A.M.; Rode, B.M. Loeffler, H. J. Phys. Chem. A 2002, 106, 6783.

18. Mohammed, A.M. Bull. Chem. Soc. Ethiop. 2006, 20, 121.

19. Iglesias-Yagüe, J.; Mohammed, A.M.; Loeffler, H.H.; Rode, B.M. J. Mol. Struct.: Theochem 2003, 620, 15.

20. Loeffler, H.H.; Mohammed, A.M.; Inada, Y.; Funahashi, S. Chem. Phys. Lett. 2003, 379, 452.

21. Mohammed, A.M.; Loeffler, H.H.; Inada, Y.; Funahashi, S. J. Mol. Liq. 2005, 119, 55.

22. Rode, B.M.; Islam, S.M. Z. Naturforsch Teil A 1991, 46, 357.

23. Yongyai, Y.; Kokpol, S.; Rode, B.M. Chem. Phys. 1991, 156, 403.

24. Probst, M.M. Chem. Phys. Lett. 1987, 137, 229.

25. Langford, C.H.; Gray, H.B. Ligand Substitution Processes, Benjamin: New York; 1965.

26. Helm, L.; Merbach, A.E. Chem. Rev. 2005, 105, 1923.

27. Rotiznger, F.P. Chem. Rev. 2005, 105, 2003.

28. Inada, Y.; Loeffler, H.H.; Rode, B.M. Chem. Phys. Lett. 2002, 358, 449.

29. Schwenk, C.F.; Loeffler, H.H.; Rode, B.M. Chem. Phys. Lett. 2001, 349, 99.

30. Hermansson, K.; Wojcik, M. J. Phys. Chem. B 1998, 102, 6089.

31. Inada, Y.; Mohammed, A.M.; Loeffler, H.H. Funahashi, S. Helv. Chim. Acta 2005, 88, 461.

32. Loeffler, H.H.; Mohammed, A.M.; Inada, Y.; Funahashi, S. J. Comp. Chem. 2006, 27, 1944.

33. Mohammed, A.M. Bull. Chem. Soc. Ethiop. 2008, 22, 423.

34. Valleau, J.P.; Torrie, G.M. Chem. Phys. Lett. 1974, 28, 578.

35. Valleau, J.P.; Torrie, G.M. Statistical Mechanics, Part A: A Guide for Monte Carlo for Statistical Mechanics, Berne, B.J. (Ed.), Plennum: New York; 1977.

36. Kumar, S.; Rosenberg, J.M.; Bouzida, J.D.; Swendsen, R.H.; Kollman, P.A. J. Comput. Chem. 1995, 16, 1339.

37. Boczko, E.M.; Brooks III, C.L. Science 1995, 269393.

38. Boczko, E.M. Brooks III, C.L. J. Phys. Chem. 1993, 97, 4509.

39. Jorgensen, W.L. Acc. Chem. Res. 1989, 22, 184.

40. Kumar, S.; Bouzida, J. D.; Swendsen, R. H.; Kollman, P.A.; Rosenberg, J.M. J. Comput. Chem. 1992, 13, 1011.

41. Roux, B. Comput. Phys. Commun. 1995, 91, 275.

42. Frisch, M.J.; Trucks, G.W.; Schlegel, H.B.; Scuseria, G.E.; Robb, M.A.; Cheeseman, J.R.; Zakrzewski, V.G.; Montgomery, J.A.Jr.; Stratmann, R.E.; Burant J.C.; Dapprich, S.; Millam, J.M.; Daniels, A.D.; Kudin, K.N.; Strain, M.C.; Farkas, O.; Tomasi, J.; Barone, V.; Cossi, M.; Cammi, R.; Mennucci, B.; Pomelli, C.; Adamo, C.; Clifford, S.; Ochterski, J.; Petersson, G.A.; Ayala, P.Y.; Cui, Q.; Morokuma, K.; Salvador, P.; Dannenberg, J.J.; 
Malick, D.K.; Rabuck, A.D.; Raghavachari, K.; Foresman, J.B.; Cioslowski, J.; Ortiz, J.V.; Baboul, A.G.; Stefanov, B.B.; Liu, G.; Liashenko, A.; Piskorz, P.; Komaromi, I.; Gomperts, R.; Martin, R.L.; Fox, D.J.; Keith, T.; Al-Laham, M.A.; Peng, C.Y.; Nanayakkara, A.; Challacombe, M.; Gill, P.M.W.; Johnson, B.; Chen, W.; Wong, M.W.; Andres, J.L.; Gonzalez, C.; Head-Gordon, M.; Replogle, E. S.; Pople, J.A. Gaussian 98 Revision A.11, Gaussian: Pittsburgh PA; 2001.

43. Hurley, M.M.; Frenandez Pacios, L.; Christiansen, P.A.; Ross, R.B.; Ermler, W.C. J. Chem. Phys. 1986, 84, 6840.

44. Dunning, T.H. Jr. J. Chem. Phys. 1970, 53, 2823.

45. Kuchitsu, K.; Morino, Y. Bull. Chem. Soc. Jpn. 1965, 38, 814.

46. Lemberg, H.L.; Stillinger, F.H. J. Chem. Phys. 1975, 62, 1677.

47. Stillinger, F.H.; Rahman, A. J. Chem. Phys. 1978, 68, 666.

48. Bopp, P.; Jancsó, G.; Heinzinger, K. Chem. Phys. Lett. 1983, 98, 129.

49. Remsungnen, T.; Rode, B.M. J. Phys. Chem. A 2003, 107, 2324.

50. Remsungnen, T.; Rode, B.M. Chem. Phys. Lett. 2004, 385, 491.

51. Curtiss, L.A.; Halley, J.W.; Hautman, J.; Rahman, A. J. Chem. Phys. 1987, 86, 2319.

52. Floris, F.; Persico, M.; Tani, A.; Tomasi, J. Chem. Phys. Lett. 1992, 199, 518.

53. Degréve, L.; Quintale, C. Jr. J. Electroanal. Chem. 1996, 409, 25.

54. Herdman, G.J.; Neilson, G.W. J. Phys.: Condens. Matter 1992, 4, 649. 